\title{
Conflicto político y prensa federal durante la Guerra de la Triple Alianza. Entre Ríos, 1864-1867*
}

por

\author{
Mónica Alabart ${ }^{1}$
}

UNGS/UBA
Mariana Pérez ${ }^{2}$

UBA, CONICET/UNGS

Desde el comienzo de la Guerra de la Triple Alianza la prensa fue un ámbito privilegiado para la polémica y el debate dentro del escenario político. En este trabajo analizamos la prensa federal de la provincia de Entre Ríos con el propósito de indagar sobre la dinámica política entrerriana y su interrelación con la guerra. Nuestra hipótesis es que, si bien la prensa federal entrerriana mostró una constante oposición al conflicto bélico, la crítica no fue lineal a lo largo del periodo aquí analizado y estuvo subordinada a la impugnación de las políticas del presidente Bartolomé Mitre y del partido liberal.

Palabras Clave: prensa federal; Guerra de la Triple Alianza; dinámica política; representaciones políticas.

Cómo citar este artículo / Citation: Alabart, Mónica y Pérez, Mariana, "Conflicto político y prensa federal durante la Guerra de la Triple Alianza. Entre Ríos, 1864-1867", Revista de Indias, LXXIX/276 (Madrid, 2019): 551-580. https://doi.org/10.3989/revindias.2019.017.

\section{Prensa política y la Guerra de la Triple Alianza.}

La Guerra del Paraguay o de la Triple Alianza conforma una cuestión de enorme relevancia para la historia latinoamericana de la segunda mitad del siglo XIX. Constituyó la más sangrienta y demoledora guerra sudamericana del siglo,

* Una versión preliminar de este trabajo fue presentada en las $V$ Jornadas Internacionales de Historia del Paraguay, realizadas en la Universidad de Montevideo en julio de 2016.

1 malabart@ungs.edu.es, ORCID iD: https://orcid.org/0000-0001-6336-5128.

2 maperezyea@gmail.com, ORCID iD: https://orcid.org/0000-0002-2253-5773. 
que derivó en la destrucción de la economía y la sociedad paraguaya. La guerra fue, además, un episodio crucial para la consolidación de los estados nacionales del Plata y redefinió la geografía política regional. Dado que se trata de un proceso que ha concitado el interés de intelectuales e historiadores desde finales del siglo XIX, existe una abundante y variada bibliografía sobre el conflicto ${ }^{3}$. En Argentina, en los últimos años, un conjunto de trabajos denota un nuevo foco de atención en la guerra, la cual está siendo analizada desde diversas perspectivas ${ }^{4}$.

En Entre Ríos, la guerra fue muy impopular y la decisión de Justo José de Urquiza de prestarle apoyo, agudizó las tensiones presentes al interior del federalismo, erosionando fuertemente su poder como caudillo. No obstante, la historiografía entrerriana ha abordado la guerra de la Triple Alianza como problema tangencial en otras cuestiones, tales como el compromiso de Urquiza con el orden nacional o los antecedentes del movimiento jordanista ${ }^{5}$.

Un tema que ha suscitado un renovado interés es el rol de la prensa durante el desarrollo de la guerra en los países beligerantes. Como ha sido señalado por numerosos trabajos que indagan en la cultura política decimonónica, la prensa periódica era un actor clave en la arena política. Su rol no se reducía a la difusión de ideas, el discurso periodístico era profundamente performativo puesto que pretendía generar «hechos políticos»: orquestaba campañas, hacía circular rumores, articulaba redes políticas ${ }^{6}$. En Argentina, al igual que en Brasil y Uruguay, la guerra fue acompañada de una intensa conflictividad política entre grupos y partidos y provocó distintos grados y modos de resistencia. Desde el inicio de la contienda, la prensa fue un ámbi-

3 Entre la bibliografía reciente que no incluye el caso argentino mencionamos: Capdevila, 2010. Doratioto, 2002. Guinot, 2005. Whigham, 2010; 2011; 2012.

${ }^{4} \mathrm{Si}$ bien el proceso de construcción del estado nacional argentino fue uno de los temas más indagados en la renovación de la historiografía argentina tras el advenimiento de la democracia en la década de 1980, llamativamente, y a pesar del consenso sobre que la guerra de la Triple Alianza fue un hito en ese proceso, los estudios sobre la misma no formaron parte de esta renovación hasta hace relativamente pocos años. Entre los trabajos publicados recientemente que abordan el tema de la guerra, podemos mencionar: sobre el impacto de la guerra en Corrientes, Braschi, 2014; 2016 y Buchbinder, 2012: 29-48. Sobre la financiación de la guerra, Garavaglia, 2016: 1-33. Sobre memoria e historiografía, Brezzo, 2015: 95-162; 2016: 91-186. Quiñonez, 2013: 311-326.

5 Para un análisis del rol de Urquiza ver Bosch, 1963: 822-827. Sobre el jordanismo, Duarte, 1974 y Chávez, 1957. Entendemos que un estudio exhaustivo de los efectos de la guerra en la provincia es un tema todavía pendiente en la historiografía entrerriana.

Para un estudio sobre las formas de resistencia a la guerra en Entre Ríos ver Alabart, 2015: 101-131.

6 Sobre el carácter performativo del discurso periodístico ver Palti, 2007, especialmente el capítulo 3 . 
to privilegiado para el debate y la confrontación política desde donde se configuraron los argumentos a favor y en contra del conflicto, las representaciones de aliados y enemigos, el nacionalismo y las identidades partidarias.

En los últimos años se han publicado numerosos trabajos sobre la prensa paraguaya y brasileña como parte de esta renovación historiográfica ${ }^{7}$. En el caso de la Argentina, la mayor parte de los nuevos trabajos son estudios de caso centrados en la prensa porteña y correntina ${ }^{8}$.

Como señalamos, la Guerra de la Triple Alianza fue muy impopular en la provincia de Entre Ríos y profundizó las tensiones existentes al interior del federalismo entrerriano. El inicio de las hostilidades de Brasil contra los blancos en Uruguay y, posteriormente, la creación de la Triple Alianza contra Paraguay, dieron lugar a la circulación pública de opiniones disidentes a la guerra y a incrementar las críticas al presidente Bartolomé Mitre que estaban presentes desde 1862.

En este trabajo indagaremos sobre la dinámica política entrerriana y su interrelación con la Guerra de la Triple Alianza a partir del análisis de la prensa de tendencia federal de la provincia en los primeros años posteriores al inicio del conflicto. Para entonces existía en Entre Ríos una numerosa, dinámica y diversa prensa periódica que alimentaba un debate público cada vez más complejo y difícil de controlar por parte de las autoridades provinciales. Además del periódico «oficial», El Uruguay, se editaban periódicos de tendencia unitaria ${ }^{9}$ y periódicos federales «independientes» que eran órganos

7 Caballero Campos y Ferreira Segovia, 2006. Johansson, 2011: 117-138; 2012: 71-92. Silveira, 2009; 2014: 213-236. Whigham, 2012: 157-180.

8 Por ejemplo: Baratta, 2012a: 82-98; 2012b: 83-108; 2013: 75-96; 2014: 41-53. Braschi, 2003. Buchbinder, 2012: 29-48. De Marco, 2003.

Para el caso de la prensa liberal tucumana: Navajas, 2009. Un análisis comparativo entre prensa paraguaya y porteña en Johansson y Sujatovich, 2012: 99-111.

9 En este trabajo los términos «unitario» y «liberal» (o «partido unitario»y «partido liberal») son equivalentes. Si bien los miembros del partido liberal no se definían como «unitarios» (aunque se proclamaban herederos de ese partido surgido en Buenos Aires en la década de 1820), desde el campo del federalismo «liberal» y «unitario» eran sinónimos y expresión de una misma identidad política. Por otro lado, las bases programáticas de los partidos «federal» y «liberal/unitario» eran similares: ambos se adherían al liberalismo como doctrina económico-política y al sistema federal de gobierno. Por lo tanto, las filiaciones partidarias y las identidades políticas se definían a partir de complejas configuraciones de redes de poder locales y tradiciones políticas, que, lógicamente, variaban según cada realidad provincial. En el caso del federalismo entrerriano, su identidad se constituía fundamentalmente a partir de un fuerte sentimiento anti porteño y la defensa de la autonomía provincial. Para un análisis de las identidades partidarias en la década de 1860 en Argentina ver De la Fuente, 2007 y Míguez, 2013. 
de propaganda del federalismo y reconocían a Urquiza como líder del partido, pero mantenían cierta autonomía discursiva del gobierno provincial y del caudillo.

A diferencia de lo sucedido en otros espacios provinciales, en Entre Ríos la mayoría de los periódicos desarrolló un discurso de impugnación a la guerra, a las políticas del presidente Mitre y al Imperio del Brasil desde el inicio del conflicto ${ }^{10}$. Cinco son los periódicos que analizaremos: El Paraná y El Eco de Entre Ríos (editados en la ciudad de Paraná); El Pueblo Entrerriano y El Porvenir (de la ciudad de Gualeguaychú) y El Republicano (de Concordia $)^{11}$. Todos ellos se reconocían defensores del federalismo y compartían un discurso de oposición a la guerra contra Paraguay. Esta identidad partidaria y discursiva era reconocida y reafirmada por los editores, los cuales reproducían las notas o editoriales publicadas en los periódicos afines. En tal sentido, es claro que editar un periódico era concebido como una acción política colectiva y la aparición de «nuevos colegas» que se sumaban a la «lucha» se celebraba con entusiasmo mientras que el cierre o clausura de algún periódico afín era señalado con preocupación ${ }^{12}$.

En tanto que periódicos de tendencia federal, reivindicaban el liderazgo de Urquiza como jefe del partido federal y caudillo entrerriano, pero no eran periódicos «oficiales»y, por lo tanto, no siempre sus opiniones se adecuaban

10 La prensa en otros espacios provinciales, con la excepción de Buenos Aires, está muy poco estudiada en este período, por lo tanto, esta afirmación todavía debe ser corroborada. Sabemos que en Buenos Aires las voces disidentes a la guerra en la prensa fueron minoritarias y en Tucumán inexistentes, mientras que en Corrientes existieron periódicos favorables al Paraguay al inicio de la contienda, que luego desaparecieron (Baratta, 2012b. Braschi, 2003. Buchbinder, 2012. Navajas, 2009).

11 El Paraná se publicó entre 1864 y 1867. Su editor responsable era Jorge Alzugaray y su principal redactor, Eusebio Ocampo, diputado nacional por Entre Ríos. El Eco de Entre Ríos se editó entre julio de 1866 y enero de 1867, su redactor y editor responsable fue Floreano Zapata. El Pueblo Entrerriano se publicó entre 1863 y 1867. Hasta mediados de 1864, su redactor principal fue Olegario Andrade y entre sus colaboradores se encontraba Francisco F. Fernández, un conocido partidario de López Jordán. En julio de 1864 Olegario Andrade fundó El Porvenir, que se editó hasta enero de 1867. El editor responsable de El Pueblo Entrerriano fue a partir de entonces, Eugenio Gómez y uno de los principales redactores, Emilio Funes. El Republicano, fue editado en la ciudad de Concordia por Eduardo Gordon durante el año de 1865.

12 Por ejemplo, en julio de 1866 El Porvenir anunciaba la aparición de El Eco de Entre Ríos con estas palabras: «Donde el Litoral había desaparecido dejando un rastro de sombra, se levanta hoy el Eco de Entre Ríos, campeón gallardo y generoso de la causa republicana. Donde el Gualeguay había renegado de sus antiguas creencias, anuncia ya su aparición el Progreso (...). Los claros se han llenado. ¡Sean bienvenidos los soldados voluntarios que ingresan a las filas de la prensa entrerriana!», "Los claros se llenan”, El Porvenir, 18-7-1866. 
a los lineamientos políticos de Urquiza o del gobierno de la provincia ${ }^{13}$. Como prensa «militante», mantenían constantes debates con la prensa unitaria de la provincia (sobre todo con La Democracia, el periódico opositor de mayor circulación) y con los periódicos liberales de Buenos Aires ${ }^{14}$.

Consideramos que hay tres momentos en torno a los cuales se articularon los principales tópicos del discurso periodístico sobre el conflicto. El primero corresponde al período abierto en la segunda mitad de 1864 con la invasión brasileña a Uruguay, hasta la invasión paraguaya a Corrientes en abril de 1865. El segundo, se abre con la entrada de Argentina en la guerra contra Paraguay en mayo de 1865 y concluye en noviembre de dicho año, cuando se produce el segundo desbande de las tropas entrerrianas reclutadas para ir al frente paraguayo. El tercero, se inicia a fines de 1865 y culmina en enero de 1867, cuando el gobierno nacional ordena la clausura de los periódicos que aquí se analizan.

\section{LA CUESTIÓN BRASILEÑA-ORIENTAL Y LA OPOSICIÓN A LA GUERRA}

El preludio del conflicto comenzó en abril de 1863 cuando el general Venancio Flores, del Partido Colorado, con el apoyo encubierto de liberales mitristas, desembarcó en la costa oriental para derrocar al presidente del Partido Blanco Bernardo Berro, dando comienzo a una guerra civil en Uruguay ${ }^{15}$. Los blancos uruguayos esperaban la ayuda de la provincia de Entre Ríos para detener la invasión. Pero Urquiza, alineado con el gobierno nacional encabezado por Mitre, adoptó una posición neutral frente al conflicto. Esta posición del general entrerriano no impidió que un grupo de federales disidentes fueran estrechando vínculos con los blancos y brindaran ayuda para contener la invasión de Flores ${ }^{16}$.

13 El rol de periódico «oficial» le cabía a El Uruguay, editado en la capital de la provincia, Concepción del Uruguay, por Julio Victorica. Publicaba los decretos, leyes y demás avisos del gobierno de la provincia y era reconocido por el resto de la prensa entrerriana y por la porteña como prensa «oficial» que reproducía las opiniones de Urquiza y del gobierno de la provincia, aunque su redacción se declaraba «independiente».

14 Un análisis de la prensa federal y unitaria en la provincia y sus vínculos con los poderes políticos locales en Pérez, 2015a: 133-160; 2015b: 35-58.

15 Si bien el presidente Mitre declaró y mantuvo una neutralidad formal, buques argentinos contrabandeaban armas para los colorados de Flores y los liberales porteños les dieron su apoyo.

16 El lazo de unión entre los blancos y los federales entrerrianos fue el presbítero Domingo Ereño. En su casa de Concepción Del Uruguay, se alojó el general uruguayo Diego Lamas 
La guerra civil uruguaya tomó otro carácter a partir de la intervención brasileña en el país oriental. Las relaciones entre el Imperio brasileño y el presidente Berro habían sido tensas desde el comienzo de su gobierno y se manifestaron en una serie de protestas diplomáticas por parte de Brasi1 ${ }^{17}$. El fracaso de estas gestiones derivó en la invasión de las fuerzas brasileñas, que en octubre de 1864 se sumaron al ejército de Flores, con el objetivo de derrocar al gobierno blanco. Ante esta situación, el presidente paraguayo Francisco Solano López con la decisión de frenar el avance del Imperio en la región, invadió el Mato Grosso y declaró la guerra a Brasil en diciembre.

Los periódicos entrerrianos siguieron el conflicto uruguayo desde su inicio. El Paraná, El Porvenir y El Pueblo Entrerriano informaron sobre el rumbo que iban tomando los acontecimientos, transcribieron documentos oficiales, publicaron notas de la prensa argentina y uruguaya, y fundamentalmente utilizaron sus páginas para expresar su oposición a la invasión de Flores, a la intervención brasileña y a polemizar con los periódicos de tendencia «unitaria» de Buenos Aires. Aún antes de que las fuerzas brasileñas invadieran el territorio uruguayo, los diarios entrerrianos ya esbozaban algunas de las principales líneas sobre las cuales girarían los argumentos contra la Guerra de la Triple Alianza: las ambiciones expansionistas del Imperio y las peligrosas consecuencias para el sistema republicano y la integridad territorial y política del resto de las naciones del Plata.

Así, por ejemplo, para El Paraná, con la invasión brasileña estaba en juego el equilibrio político de la región, por lo tanto, existía un interés común de las naciones del Plata contra el Imperio del Brasil y, frente a ese peligro, las cuestiones de partido no debían importar. El Paraná reconocía que sus simpatías estaban del lado de los blancos, pero afirmaba que, si Brasil hubie-

en cumplimiento de una misión reservada encomendada por el presidente Berro para entrevistarse con Urquiza. Lamas que conocía la buena disposición de Waldino Urquiza, Telmo López, Ramón Gallo y otros, sugirió a López Jordán organizar una campaña política que no podría contener el general Urquiza. En septiembre de 1863, Waldino Urquiza junto a otros jefes y oficiales con una fuerza de 500 hombres bien armados y pertrechados pasaron al Uruguay para ayudar a los blancos. Resulta difícil suponer que Urquiza era ajeno a esos preparativos, pero no tomó ninguna medida para impedirlo y mantuvo a lo largo de la contienda su posición neutral, ofreciéndose como mediador para un acercamiento entre las partes en conflicto. Duarte, 1974: 62-63.

17 La presencia de un número importante de hacendados del estado de Río Grande do Sul que ocupaban tierras del lado de la frontera uruguaya para expandir sus empresas ganaderas se convirtió en una fuente de conflicto. Mientras el gobierno uruguayo intentaba asegurar el control sobre su territorio, la corona brasileña protestaba por lo que consideraba un atropello a sus intereses y los derechos supuestos de sus súbditos, Sabato, 2012: 148. 
se ido con su ejército a apoyarlos, de la misma manera habría censurado su intervención, porque ella acabaría «por extinguir la nacionalidad oriental y su forma de gobierno». Por consiguiente, manifestaba su simpatía con Paraguay que había levantado la voz para conjurar ese peligro y, además, defender el sistema republicano:

[Paraguay] El modesto pendón de una República va a ponerse al frente del águila orgullosa de un Imperio, y en su reto van a jugar tal vez la vida de dos principios, que desde mucho tiempo ha se vienen disputando sordamente la supremacía de América ${ }^{18}$.

Durante diciembre y los primeros días del año 1865 , la sociedad entrerriana se vio sacudida por los combates y el bombardeo a la Villa de Paysandú ${ }^{19}$. En El Paraná, El Porvenir y El Pueblo Entrerriano se publicaron extensas notas informando lo que había acontecido en la ciudad vecina y los editoriales y artículos fueron adquiriendo un tono más crítico con respecto al Imperio brasileño, los colorados, la prensa unitaria y la política del gobierno nacional argentino frente al conflicto. Se levantaron voces de protesta por el incendio de la «villa mártir», se escribieron cantos y poemas en homenaje al valor de su «pueblo heroico», cuya gloria estaba en haber resistido el «ataque bárbaro» de la escuadra brasileña. En los periódicos se publicaron documentos oficiales, como los partes de la defensa de la ciudad; notas en colaboración en las que testigos presenciales suministraron la nómina de los jefes y oficiales sacrificados después del combate; cartas que describían los horrores perpetrados por las fuerzas de Brasil y su aliado Flores ${ }^{20}$. En El Porvenir se publicó un poema a Paysandú firmado por Un entrerriano ${ }^{21}$ y varios meses después en la imprenta de El Republicano se editó el folleto "Nueva Numancia" escrito por «Un Re-

18 “El Brasil y el Paraguay”, El Paraná, 3-12-1864 (Hemeroteca de la Universidad Nacional de la Plata, La Plata [HUNLP]).

19 A fines de 1864 Venancio Flores con ayuda de la escuadra brasileña puso sitio a la ciudad de Paysandú que resistió durante un mes los combates. La defensa de la ciudad estuvo a cargo del general blanco Leandro Gómez. Una tregua le permitió evacuar a parte de sus pobladores a la isla vecina de la Caridad, de jurisdicción argentina. La violencia de los bombardeos desde río y tierra destruyó completamente la ciudad, aunque los pobladores resistieron hasta caer derrotados por un ataque final de la escuadra brasileña el 2 de enero de 1865. Los oficiales rendidos fueron ejecutados y muchos blancos emigraron a Entre Ríos donde fueron bien recibidos. Duarte, 1974: 57-68.

20 El Paraná, 31-12-1864; 27-12-1864; 7-1-1865; 12-1-1865, 17-1-1865 (HUNLP).

21 Sus primeras estrofas dedicadas a Venancio Flores comenzaban: «¿Dónde están Flores tus triunfos? ¿En dónde la victoria, que, con sangriento empeño, pensabas alcanzar? ¿En dónde está la fama de tu gloria? Tu nombre de entre el fango recogerá la historia, Y al lado de Almonte grabado ha de quedar», "Paysandú" de Un Entrerriano, en El Porvenir, 23-12-1864 (HUNLP). 
publicano», con datos históricos sobre la defensa y toma de Paysandú22. Los editores de El Paraná, en una larga serie de notas, acusaron a La Nación y La Tribuna de Buenos Aires de haberlos injuriado por poner en duda las noticias que habían brindado sobre el asalto a la ciudad y de regalarles, con la profusión de siempre, los epítetos de «bárbaros», «chusma», «retrógrados», «mazorqueros de Entre Ríos», porque habían condenado la traición de Paysandú y los asesinatos cometidos hacia valientes militares, porque rechazaban la alianza con Brasil y porque querían mantener la dignidad de la República y la paz interior ${ }^{23}$.

Pero, ¿quiénes eran los verdaderos bárbaros? La pregunta era retomada en varias notas. Para los editores de los periódicos entrerrianos la barbarie había entrado en escena con el asedio a Paysandú, el cual había sido «un hecho sólo digno de la barbarie de los cipayos» ${ }^{24}$. Por más que el «espíritu de partido» se empeñara en oscurecer la hecatombe de Paysandú, ella no tenía precedente en el Río de la Plata. Sin embargo, la prensa de Buenos Aires celebraba ese «crimen» realizado en nombre de un partido. Por el contrario, ellos se consideraban, ante todo, hombres de principios y acusaban al gobierno de Mitre de colocar las identificaciones partidarias sobre los principios, lo que era claramente perjudicial para los intereses de la nación ${ }^{25}$.

En los primeros meses de 1865, los periódicos federales profundizaron su posición en contra de una posible alianza con Brasil, a la que calificaban de «criminal» ${ }^{26}$. Denunciaban que la política de Mitre no era neutral sino pro brasileña, y que Brasil estaba haciendo su juego para afirmar su poder en la región, cuestión que sí había advertido el presidente paraguayo. Asimismo, distintas editoriales reforzaron la dicotomía entre el sistema político y social brasileño y el de las repúblicas americanas. Sostenían que el Imperio, con «su ejército de esclavos», tenía como objetivo avasallar a estas con sus «pueblos

${ }^{22}$ El Republicano, 30-10-1865 (HUNLP). El folleto se publicitaba en la cartelera del periódico. El aviso decía que contenía las biografías del general entrerriano Lucas Piris, del general Leandro Gómez, del comandante Pedro Rivero y del coronel Emilio Raña. Un tomo de cerca de 200 páginas, de buena impresión, que costaba 2 pesos bolivianos.

23 Además, señalaban irregularidades en la circulación de la correspondencia pública, algunos periódicos llegaban «truncos» y algunos no llegaban «ni truncos siquiera», como El Pueblo, que no lo recibían hacía tres o cuatro semanas, justo cuando este periódico combatía la injerencia armada de Brasil en la cuestión Oriental. Si bien no ponían en duda el accionar del Ministro de Interior Rawson como para pensar que era una medida oficial calculada con objetivos políticos, sí creían que se debía al «abuso de algún subalterno que en vez de estar en un empleo de confianza debiera estar en un presidio», El Paraná, 17-1-1865 (HUNLP).

24 "La barbarie en escena", El Paraná, 17-1-1865 (HUNLP).

25 Ver Ocampo Eusebio, "Y van dos" y "La política de la inercia nos tiene en la acefalía", El Paraná, 10-1-1865; "Siempre lo mismo”, El Paraná, 17-1-1865 (HUNLP).

26 "Mala Política”, El Paraná, 10-1-1865 (HUNLP). 
libres y sus instituciones democráticas». El redactor de El Porvenir lo expresaba de la siguiente manera:

¿Qué montones de bultos son aquellos que se acercan a las murallas de Montevideo, dejando tras sus pasos, un ancho surco de devastación? Los negros de Pedro II, empujados a cazar hombres libres, como cazaban antes de su cautiverio, los tigres y las panteras en los bosques impenetrables de África. Son las hordas de la barbarie imperial que vienen a derribar las puertas del templo de la República, para sentar en sus aras el ídolo caduco de las viejas monarquías, para prostituir la dignidad humana y envilecer los destinos de la civilización. ¿Quién los ha traído a tirones por el camino que otra vez recorrieron impelidos por el pánico de la derrota? El partido maldito que tiene por jefes a los dos apóstatas de la democracia, a Flores en la República Oriental y a Mitre en la República Argentina ${ }^{27}$.

Mediante la antinomia «civilización-barbarie», se deslegitimaba la intervención de Brasil, cuya monarquía esclavista encarnaba la «barbarie» que atentaba contra las instituciones republicanas, sus libertades y sus destinos de civilización. Con el mismo argumento, los redactores de El Porvenir justificaban la intervención de Paraguay en el conflicto: el presidente López no solo intervenía en la contienda para frenar el expansionismo de Brasil, sino que encabezaba la lucha de la república contra la monarquía y de los pueblos libres contra el Imperio esclavócrata. Comentando el avance de las tropas paraguayas, así lo expresaban:

Las legiones republicanas, hacen estremecer bajo las plantas la tierra calcinada con el sudor de los esclavos... Ahí está el Paraguay, airoso paladín del derecho de las nacionalidades, del equilibrio de los pueblos que riega y fecunda el Plata; ahí está abriendo de par en par las ferradas puertas de los calabozos del imperio esclavócrata, derribando al empuje de sus armas las podridas columnas del trono que se levanta en las playas del Atlántico como el poste de la ignominia de una raza ${ }^{28}$.

Por su parte, El Paraná sin adoptar un discurso de defensa incondicional a la posición paraguaya, planteaba que Paraguay estaba en relaciones de amistad con la República Argentina y criticaba con dureza a la prensa de Buenos Aires que publicaba «mentiras ridículas e inexactitudes». En ese sentido era frecuente la publicación de notas del periódico paraguayo Semanario para desmentir a la prensa porteña ${ }^{29}$.

27 "La responsabilidad de la sangre" en El Porvenir, publicado en El Paraná, 11-2-1865 (HUNLP).

28 El Porvenir, 9-2-1865 (HUNLP).

29 Por ejemplo, en marzo, publicaron un artículo con respecto al tratamiento de los prisioneros brasileños en Asunción, acompañado de cartas escritas por los propios detenidos, El Paraná, 16-3-1865 (HUNLP). 
Durante los primeros meses del año 1865, los periódicos entrerrianos invocaron constantemente la figura de Urquiza. Todos cubrieron sus intentos de mediación en el conflicto oriental, como así también el funeral de su hijo José y los honores fúnebres que presidió, brindados a las víctimas de Paysandú. Sin embargo, se advierten las tensiones que su política de neutralidad estaba generando al interior del Partido Federal.

En febrero, una editorial de El Porvenir (y reproducida por El Paraná) cuestionaba abiertamente la neutralidad de Urquiza. Si bien reconocía que el general, «lógico con su pasado de gloria», había condenado la invasión de Flores a Uruguay, manifestado sus antipatías profundas hacia el Imperio del Brasil y había obligado - a través de sus intervenciones - al gobierno argentino a ser respetuoso con Paraguay, era necesario más. Le exigían:

Que rompa para siempre la solidaridad de los hechos que están labrando la desgracia de los pueblos.

Que sea en 1865 el héroe de 1852. Que reverdezcan sobre su enhiesta sien los laureles de Caseros, y que arroje su espada en la balanza de los destinos de la democracia americana, que conquiste garantías para el porvenir que está preñado de tempestades ${ }^{30}$.

\section{ENTRE RÍOS DE PIE: TODOS UNIDOS POR LA «CAUSA NACIONAL»}

En marzo de 1865 el gobierno paraguayo solicitó al argentino permiso para pasar con sus tropas por el territorio nacional con el propósito de invadir Río Grande do Sul. El presidente Mitre denegó ese permiso argumentando la absoluta neutralidad del país. El 13 de abril fuerzas armadas de Paraguay atacaron dos buques argentinos estacionados en el puerto de Corrientes y al día siguiente ocuparon la ciudad. En consecuencia, Mitre instó a los ciudadanos a prepararse para la guerra y el primero de mayo el gobierno argentino firmó el Tratado de la Triple Alianza con Brasil y Uruguay, por el cual los signatarios acordaron una alianza ofensiva-defensiva «en la guerra provocada por el gobierno del Paraguay» ${ }^{31}$.

30 "El General Urquiza”, El Porvenir, en El Paraná, 25-2-1865 (HUNLP).

31 La concreción de la alianza se hizo pública pero no los términos del Tratado, que se acordó permanecieran secretos hasta que se hubieran logrado los objetivos. Además de la alianza militar, el acuerdo establecía los prerrequisitos para el establecimiento de la paz. En el plano bélico, el plan de operaciones militares aliado consistía en llevar la guerra a territorio paraguayo y hacer que las operaciones militares convergieran en la fortaleza de Humaitá, vía de acceso para la toma de Asunción. En otros puntos se determinaron las fronteras entre Paraguay, Argentina y Brasil. Asimismo, se estableció que la guerra se llevaba a cabo contra el 
A los pocos días de la invasión paraguaya a Corrientes el presidente Mitre le envió una carta al general Urquiza en la que le informaba lo sucedido, afirmaba la necesidad de reivindicar el ultraje recibido y lo designaba oficialmente jefe de la Guardia Nacional de Entre Ríos, por lo que debía levantar un cuerpo de ejército de cinco mil hombres para marchar hacia Corrientes ${ }^{32}$. Si algunos sectores esperaban que Urquiza, como jefe del federalismo, abandonara la lealtad que había manifestado desde Pavón con el gobierno de Mitre, sus esperanzas se vieron frustradas. Para el líder entrerriano, la agresión externa le daba a la guerra una dimensión nacional y requería la participación de todos los argentinos. Asimismo, confiaba en que la guerra eliminaría las divisiones políticas internas ${ }^{33}$. En consecuencia, Urquiza respondió inmediatamente al pedido del presidente y ordenó la movilización de las fuerzas de la provincia hacia el campamento de Calá, la base de operaciones de su ejército, ubicado en Concepción del Uruguay.

Los diarios de Buenos Aires celebraron la noticia: "Urquiza se pone al servicio de la nación", "Marcha contra el déspota de Paraguay", publicaron la proclama a sus tropas y la carta enviada al presidente Mitre ${ }^{34}$. Por su parte, el periódico oficial El Uruguay (que semanas antes se había manifestado en contra de que el gobierno argentino denegase el paso al ejército Paraguayo) rápidamente se ocupó de afirmar el compromiso de la provincia en la defensa del honor nacional, dejaba en claro que Paraguay estaba haciendo la guerra a los argentinos, y no sólo a Mitre y su círculo, y que la guerra no era cuestión de partidos sino una «causa nacional» ${ }^{35}$.

Lamentablemente, la mayor parte de los ejemplares de los diarios federales entrerrianos correspondientes al año 1865 se han extraviado. Sin embargo, los comentarios de la prensa porteña, la reproducción de algunas notas en sus

Gobierno de Paraguay y no contra su pueblo, de allí se derivaba el compromiso de no deponer las armas hasta el derrocamiento de Francisco Solano López. También quedaba prohibida cualquier iniciativa de paz negociada por parte de alguno de los signatarios del acuerdo de manera unilateral, sin conocimiento de los otros. Doratioto, 2008.

32 Bartolomé Mitre a Justo J. de Urquiza, Buenos Aires, 17-4-1865, citado en Archivo del General Mitre..., 1911: 2.

33 «Ha llegado el momento en que las palabras deben hacer lugar a los hechos. Nos toca combatir de nuevo bajo la bandera que reunió en Caseros a todos los argentinos. Me congratulo de ello porque la felicidad de esta campaña fiada al tino y al patriotismo de V.E mientras dará gloria a la República puede dar por resultado seguro extirpar del todo las disensiones políticas que antes han dividido al país», Urquiza a Mitre, Concepción del Uruguay, 19-41865, citado en Archivo del General Mitre..., 1911: 112.

34 La Proclama publicada en los diarios era un llamado a las tropas entrerrianas a acudir en la defensa del honor nacional vulnerado, en El Nacional, 21-4-1865 (HUNLP).

35 "Importante de Corrientes", El Uruguay, 4-5-1865 (HUNLP). 
páginas y la correspondencia sostenida entre Urquiza y otros miembros del partido federal, brindan interesantes indicios sobre el tono del discurso adoptado a partir de la invasión paraguaya y el ingreso de la Argentina en la guerra.

En los días posteriores a la invasión de Corrientes, la prensa federal entrerriana continuó atacando a la política del presidente Mitre y manifestando su apoyo a Paraguay. Por ejemplo, tras el llamado de Mitre a reunir el ejército, a marchar sobre Corrientes y a tomar Asunción en tres meses, El Porvenir, en una extensa nota, señalaba que era poco probable el éxito de la campaña militar. Según el periódico, Paraguay contaba con un poderoso ejército y con el apoyo de la «gran mayoría del país, que espía el momento de sacudir el yugo del tutelaje de Buenos Aires». Por el contrario, aún si Mitre lograse reclutar un gran número de hombres, su ejército sería débil porque la guerra era la expresión de los intereses de un partido y no de la patria, por lo tanto, altamente impopular:

Es todo el poder de la nación, poder bastante para arrollar más numerosas legiones, porque el valor es ingenio en el soldado argentino, pero el valor sin el entusiasmo y la fe es una espada en manos de un ciego y en esta lucha no puede haber entusiasmo ni fe porque no es a la patria a quien se sirve, sino a un partido de caballeros de industria, que no contentos con haber robado los tesoros de la nación, quieren chuparle hasta la sangre ${ }^{36}$.

Asimismo, El Porvenir auguraba una inminente rebelión en las provincias del interior y Santa Fe, por lo tanto, en breve al presidente solo le quedarían las exiguas tropas porteñas y las de Entre Ríos, que únicamente tenían en «esta lucha males y lutos que recoger». En suma, la victoria era casi imposible ${ }^{37}$.

Este tipo de artículos generaban indignación en la prensa porteña. En un editorial de El Nacional del 19 de abril, se recordaba que la prensa «roja» entrerriana había repetido hasta el «fastidio» que, en la lucha entre Brasil y Paraguay, Entre Ríos estaba de parte del «tirano» López, llegando a decir que reaccionaría contra el gobierno argentino, uniéndose a Paraguay, si éste se aliaba con Brasil. Pero el peligro de estas palabras no se medía por el «eco que ellas tenían en la opinión pública de aquella provincia, sino porque todo el mundo sabía que esa prensa era paga por el general Urquiza o por su orden y sostenida por la influencia de ese caudillo». Si bien el redactor no dudaba [BNA]).

36 Reproducido en La Tribuna, 25-4-1865 (Biblioteca Nacional Argentina, Buenos Aires

37 Idem. Este discurso era interpretado por la prensa porteña como un llamado a la insurrección. 
de que Urquiza asumiría el rol que le cabía como jefe de las milicias de su provincia y no se convertiría en un traidor, ponía en cuestión qué harían sus subalternos y esperaba que el general los obligara a cumplir con sus órdenes ${ }^{38}$.

En ese nuevo contexto, la respuesta que demandaba la prensa liberal de Urquiza no se hizo esperar. En abril, respondiendo a un cuestionamiento de Urquiza acerca del comportamiento de la prensa, Olegario de Andrade, redactor de El Porvenir, le escribía:

... debo decirle que hasta el 20 del presente, fecha en que conocí la proclama de V.E. ataqué con todas mis convicciones la política del gobierno nacional y defendí al Paraguay, con cuya causa en las cuestiones del Plata había simpatizado. Pero desde esa fecha no ha salido, ni saldrá de mi pluma una sola palabra que contraríe los propósitos de V.E., porque soy entrerriano, y porque V.E. debe contar con el corazón y con el brazo de todos los entrerrianos, y porque como hombre de partido, tengo confianza en el tino y patriotismo de V.E. ${ }^{39}$.

Días más tarde, junto a Francisco Fernández, publicó una breve nota en El Porvenir en la que se anunciaba a los lectores que, dado que se había decretado estado de sitio y la movilización de las tropas entrerrianas bajo la orden de Urquiza, y atendiendo a «la situación y las complicaciones que encierra», harían un «paréntesis a los debates de la política militante». No obstante, afirmaban que su «programa» no había «concluido»:

Los intereses, el porvenir, y la gloria de Entre Ríos, han de ser siempre nuestra divisa, y si ellos exigen nuevamente el pobre concurso de nuestra inteligencia y de nuestro patriotismo, lo tendrán siempre decidido ${ }^{40}$.

La carta y la nota resultan interesantes porque en ellas Andrade y Fernández explícitamente manifiestan que su posición respecto a la guerra no ha cambiado. El giro discursivo se debe únicamente a la decisión de obedecer a Urquiza en tanto líder del Partido Federal. En tal sentido, la moderación abrupta del discurso no hace más que resaltar las tensiones que el inicio de la guerra había generado al interior del federalismo entrerriano: en este caso Andrade y Fernández se habían encontrado frente a la disyuntiva de seguir con su prédica (acorde a la tradición anti porteña y anti unitaria de la prensa federal) o desconocer el liderazgo de Urquiza. Ésta última opción no era todavía políticamente viable.

\footnotetext{
38 "Entre Ríos" en El Nacional, 19-4-1865 (BNA).

39 Olegario de Andrade a Justo J. de Urquiza, Gualeguaychú, 25-4-1865, Archivo General de la Nación Argentina, Buenos Aires [AGN], Fondo Urquiza [FU], 1734.

40 "Paréntesis", El Porvenir, publicado en La Tribuna, 7-5-1865 (BNA).
} 
Las «recomendaciones» de mesura se hicieron llegar también al El Republicano. El 8 de mayo, su redactor responsable, Eduardo Gordon, fue amonestado por el jefe político del Departamento de Concordia por haber vertido ideas «contradictorias y subversivas» a la marcha del gobierno. La noticia fue informada en los diarios de Buenos Aires y también en El Uruguay, cuyos redactores comentaban que no habían visto los artículos pero aplaudían el proceder del funcionario porque «confiaban en que debía tener razones muy poderosas para hacerlo» ${ }^{41}$. Una carta firmada por Urquiza dirigida al redactor del periódico amonestado acompañaba la nota. En ella afirmaba que el señor redactor era testigo de que en la provincia de Entre Ríos, como en ninguna otra, se había ejercido el derecho de publicar sus ideas por la prensa sin censura previa. En tiempos de paz nada había que decir, pero en las circunstancias que atravesaba el país, la ley sería la que «salve y una» la patria. Por lo tanto, las prédicas que debían publicarse en la prensa eran «las que unan, las que amalgamen las ideas, las que uniformen la opinión, puesto que la independencia y la soberanía de la nación deben ser una para el ciudadano» ${ }^{42}$. Después de estas observaciones, le rogaba que no escribiera, ni publicara por la imprenta de su propiedad, ni a través del periódico, artículos que «desconceptúen y lastimen» la guerra en la que está comprometida la honra de la Argentina. Finalmente, deseaba que lo dicho «bastara» para la moderación de su «ligera pluma».

En los meses siguientes, los discursos opositores a la guerra se fueron neutralizando. La prensa oficial de la provincia mostraba el compromiso con que Entre Ríos asumía la defensa del honor nacional celebrando el éxito de la convocatoria de las tropas ${ }^{43}$. Dado que en la prensa porteña no hay referencias a notas o artículos de los periódicos federales contrarios a la guerra o instando a la rebelión, suponemos que estos acompañaron la política oficial. Tampoco hallamos en la correspondencia privada de Urquiza referencias a un comportamiento indebido de la prensa federal. Sin embargo, es probable que el tono adoptado por ésta última haya sido menos entusiasta que el seguido por El Uruguay y, por supuesto, por la prensa liberal de Buenos Aires. Indicio

41 Lamentablemente no pudimos consultar el número 34 de El Republicano porque se ha extraviado, la referencia en "El Estado de Sitio", El Uruguay 11-5-1865 (HUNLP); también en El Nacional 8-5-1865 (BNA).

42 Carta de Justo J. de Urquiza al redactor de El Republicano, publicada en El Nacional, 9-5-1865 (BNA).

43 La convocatoria de las tropas entrerrianas había sido realmente exitosa en relación con otras provincias, en las que hubo una gran oposición y rebeldía frente al reclutamiento. Sobre las resistencias populares a la Guerra del Paraguay en las provincias ver Pomer, 1986. 
de esto es una breve nota de El Porvenir en la que se informaba con tono desesperanzador sobre la partida del contingente de Gualeguaychú:

Fue un día de duelo para esta población, porque este batallón se compone de los más selecto de nuestra juventud (...). Los votos íntimos del corazón de un pueblo, acompañan esos ciudadanos armados al llamamiento de la patria, que abandonan cuanto tienen de más querido en esta situación angustiosa ${ }^{44}$.

Pero hacia el final de la nota, se augura un futuro más halagüeño: se confía en que el contingente volverá pronto y ese día «no está lejano, porque grandes sucesos van a tomar la palabra en el debate de la política nacional». Asoma aquí «la prédica militante» entre los resquicios que la situación política provincial dejaba para la expresión de las disidencias.

En la noche del tres de julio, casi tres mil soldados de caballería integrantes del ejército entrerriano acantonado en las inmediaciones del arroyo Basualdo, cerca de la frontera con Corrientes, se desbandaron al grito de «Muera el presidente... Viva el General Urquiza» ${ }^{45}$.

La explicación oficial del hecho fue reproducida en El Uruguay. Allí se atribuía la deserción a la obra de algunos mal intencionados que aprovechando que Urquiza se había retirado del campamento a conferenciar con Mitre, hicieron correr la voz de que el General ya no iba marchar al frente del ejército entrerriano: «La deserción del ejército fue pues motivada por un error que algún travieso tuvo bastante habilidad para explotar a su antojo [porque] Todos sabemos que el soldado Entrerriano quiere siempre estar a las órdenes de su ilustre caudillo» ${ }^{46}$. Además, se mostraban confiados en que en menos de un mes las tropas estarían de nuevo formadas porque «si el cariño a un jefe ilustre los hizo abandonar sus filas y cometer una falta como militares»» también estarán «dispuestos a lavar esa mancha cubriéndola de gloria» ${ }^{47}$.

Sin embargo, dada la magnitud del desbande, días más tarde Urquiza decidió licenciar las tropas y ordenó a los jefes y oficiales regresar a sus departamentos para volver a convocar las fuerzas en el mes de octubre.

En los meses siguientes fue preciso incrementar la propaganda a favor de la movilización de la tropa y de la justeza de la guerra. Si bien la información sobre el discurso de la prensa federal es escasa y dispersa, las referencias disponibles indican que ésta acompañó el discurso oficial, señalando que la

\footnotetext{
44 "Partida", El Porvenir, publicado en La Tribuna, 12-7-1865 (BNA).

45 Sobre los desbandes de las tropas entrerrianas ver Alabart, 2015: 101-131.

46 "Importante del Ejército", El Uruguay, 8-7-1865 (HUNLP). Reproducido en La Tribu$n a, 12-7-1865$ (BNA).

47 Idem.
} 
guerra «contra el gobierno de López» era justa e involucraba a «todos los argentinos, sin distinción de partidos y colores» y que, por lo tanto, era un «deber y un honor» concurrir al llamado para formar el ejército. Asimismo, las notas ensalzaban el liderazgo de Urquiza, fuertemente erosionado luego de los desbandes de julio ${ }^{48}$.

Pero la moderación de la prensa federal no fue siempre la esperada por Urquiza y su círculo político más cercano. En agosto, el redactor de $E l R e$ publicano fue nuevamente amonestado, esta vez con motivo de artículos publicados que fomentaban la «tea de la discordia». Si bien los artículos habían sido en respuesta a los ataques de la prensa de Buenos Aires a Urquiza y al pueblo entrerriano, el jefe político le indicaba mediante una carta que era preferible ignorar dichas publicaciones en pos «de la unión de la gran familia argentina ${ }^{49}$.

La preocupación por que la prensa de Entre Ríos mantuviese un discurso moderado frente a las «provocaciones» de los periódicos porteños, se aprecia también en la correspondencia privada que Urquiza mantenía con distintos redactores afines al federalismo: en ella señalaba los peligros que una prosa exaltada entrañaba para la paz social en la provincia. Así, a principios de septiembre le recomendaba al redactor de El Gualeguay:

Los insultos que la prensa licenciosa derrama sobre el pueblo entrerriano deben contestarse con altura y dignidad salvando siempre la causa nacional en que nos encontramos comprometidos y no contribuyendo a la anarquía y al desquicio ${ }^{50}$.

El reclutamiento de la tropa en los meses siguientes al desbande de Basualdo, fue una tarea difícil. Los hombres no se presentaban a la convocatoria y corrían rumores de que había agitadores promoviendo la no concurrencia ${ }^{51}$. No obstante, las dificultades, hacia fines de octubre Urquiza logró concentrar una fuerza de 6000 soldados, que él mismo condujo hacia Corrientes. Pero poco antes de llegar, en Arroyo Toledo, en la noche del 4 de noviembre las tropas del Segundo Regimiento de Gualeguaychú desertaron. En los días siguientes, se sumaron las de los batallones de Victoria, Diamante, Gualeguay, Paraná y Nogoyá. Esta segunda vez Urquiza ordenó obrar con energía para

48 "Por el deber y el honor", El Republicano, reproducido en La Tribuna, 18-7-1865 (BNA) y "El Ejército Entrerriano", El Republicano, reproducido en La Tribuna, 31-10-1865 (BNA).

49 "Vuelve sobre sus pasos", La Tribuna, 10-08-1865 (BNA).

50 Justo José de Urquiza a José Broches, San José 10-9-1865, AGN, FU, 1738.

51 Manuel Navarro a J. J de Urquiza, Puntas de Cañada Grande, 23-9-1865, AGN, FU, 1738. 
detenerlos. Se aplicaron medidas disciplinarias para aquietar la provincia y evitar la formación de montoneras. Hubo ejecuciones y persecuciones en toda la provincia. Finalmente, el 20 de enero de 1866, ocho meses después de la primera convocatoria, Urquiza envió los contingentes con las tropas entrerrianas desistiendo de participar personalmente en la guerra.

En los días inmediatos posteriores a los desbandes El Republicano, El Pueblo Entrerriano y El Paraná condenaron las deserciones y las «empoñozadas lenguas» que incitaban a «la disolución del ejército». Además, se informaba a los lectores sobre el «orden y moralidad» que imperaba en el ejército $\mathrm{y}$ en la provincia ${ }^{52}$. Sin embargo, El Porvenir parece no haber seguido un tono similar. A mediados de noviembre (cuando era imperioso garantizar el orden social mientras se perseguía a los desertores) el gobernador Domínguez le hacía notar con indignación a Urquiza «las correspondencias y otros escritos que en el Porvenir de Gualeguaychú publica Don Francisco Fernandez, que hoy se encuentra en ese cuartel general». En su opinión, «cualquier medida enérgica del gobierno, se convierte en el ridículo, si no se toman medidas para cortar ese abuso» ${ }^{53}$. Rápidamente, el hijo de Urquiza, Justo Carmelo se puso en contacto con Andrade para hacerle presente «la necesidad y conveniencia de que él, en su acreditado y simpático periódico escribiese en el sentido de la unión y subordinación del pueblo entrerriano» ${ }^{54}$. Días más tarde El Porvenir retomó la moderación requerida por las autoridades ${ }^{55}$.

No obstante, las presiones sobre los periódicos federales en relación a los discursos contra el gobierno nacional y la Guerra de la Triple Alianza desaparecieron apenas unas semanas más tarde, a medida que se lograba controlar la situación política de la provincia y se hacía evidente que Urquiza no participaría en la guerra ${ }^{56}$. A partir de entonces, la guerra dejó de ser un problema de la política interna entrerriana y la posibilidad de volver al contenido y al tono discursivo anterior al comienzo del conflicto armado fue posible en Entre Ríos.

Por lo tanto, entre diciembre de 1865 y enero de 1866 los periódicos de tendencia federal retomaron la crítica y denuncia hacia el gobierno de Mitre,

52 Por ejemplo, en El Republicano ver "Ejército Entrerriano", 12-11-1865 (HUNLP), "La prédica de los malos", 16-11-1865 (HUNLP), "Una Palabra más" 19-11-1865 (HUNLP). En El Pueblo Entrerriano, "Sorpresa" y "El ejército Entrerriano", 15-11-1865 (HUNLP).

53 J. M. Domínguez a J. J. de Urquiza, Uruguay, 17-11-1865, AGN, FU, 1739.

54 J. C. Urquiza a J. J. de Urquiza, Concordia, 19-11-1865, AGN, FU, 1739,

55 J. Haedo a J. J. de Urquiza, Gualeguaychú, 18-11-1865 у J. C. Urquiza a J. J. de Urquiza, Concordia, 19-11-1865, AGN, FU, 1739,

56 Este proceso fue acompañado de la publicación de notas que señalaban que era preferible que Entre Ríos no participase en la guerra, porque sus soldados eran insultados por el gobierno nacional y su prensa. "Se asegura", El Pueblo Entrerriano, 27-11-1865 (HUNLP). 
el Brasil y la guerra. Este giro discursivo fue muy evidente y así lo hacía notar La Tribuna a propósito de un artículo publicado por El Republicano a fines de noviembre:

Consumado el escándalo de Toledo, la prensa federal de Entre Ríos empieza por fin a revelar, sin embozo, lo que negaba hasta ahora: esto es, su odio a la alianza ${ }^{57}$.

\section{VUELVEN LAS CRÍTICAS A LA GUERRA}

A partir de 1866 el conflicto se trasladó al territorio paraguayo convirtiéndose en una guerra de posiciones. Fue la etapa más larga y sangrienta de la contienda hasta la toma de la fortaleza de Humaitá en julio de 1868. Luchando en territorio desconocido las fuerzas aliadas sufrieron el hostigamiento de las guerrillas enemigas, las tropas se vieron diezmadas por enfermedades y epidemias, surgieron desavenencias entre los altos mandos y fundamentalmente se encontraron con la firme resistencia de las fuerzas paraguayas. Hasta que lograron tomar Humaitá, los aliados permanecieron dos años encerrados en un cuadrilátero sin poder avanzar sobre el territorio paraguayo. Entre mayo y septiembre de 1866 se enfrentaron en varios combates que fueron considerados triunfos por los aliados, aunque implicaron grandes pérdidas para ambos ejércitos. El 12 de septiembre de 1866 a pedido del mariscal López se realizó una reunión con Mitre en Yatatí Corá para buscar una solución al conflicto, pero no se llegó a ningún acuerdo y diez días después, en la batalla de Curupaytí, las fuerzas aliadas sufrieron su peor derrota. Las bajas fueron enormes, las operaciones de los aliados se paralizaron durante diez meses, el liderazgo de Mitre como general del ejército quedó seriamente lesionado y se reavivaron en la prensa la oposición y las críticas a la guerra, como así también, a la conducción del gobierno nacional.

En esta etapa del conflicto, los discursos de la prensa entrerriana federal fueron radicalizándose más. Las prédicas en contra de la guerra y los llamados recurrentes a la paz, se intercalaban con críticas a Mitre como general del ejército y al partido liberal. Éstas no sólo se expresaban a través de los editoriales, notas y artículos de los redactores de los periódicos, sino también por medio de las correspondencias y las cartas que enviaban los corresponsales de guerra que los editores decidían publicar ${ }^{58}$.

\footnotetext{
57 "La Alianza y los órganos de Urquiza", La Tribuna, 30-11-1865 (BNA).

58 De los periódicos federales sólo El Paraná tenía sus propios corresponsales en el frente que brindaban informes sobre la actuación de los batallones entrerrianos en el ejército aliado.
} 
Desde los primeros meses de 1866 en los que fueron llegando noticias sobre los triunfos de las fuerzas aliadas, los periódicos entrerrianos federales sostuvieron una posición crítica cuestionando esas «victorias», subrayando las pérdidas humanas, destacando la superioridad de las fuerzas paraguayas y reprobando la conducción de los generales en las operaciones militares.

La incapacidad de Mitre para conducir el ejército era constantemente señalada mediante argumentos político partidarios que eran reafirmados con informes que llegaban desde el frente. Incluso era habitual la utilización de la ironía y el humor. Con respecto al combate de Estero Bellaco ${ }^{59}$, los redactores de El Paraná comentaban que los diarios franceses que habían recibido presentaban el hecho de armas como un triunfo de los paraguayos y decían que:

El general Mitre - todo el mundo lo sabe en América - es un poeta muy distinguido. En efecto, cuando el decreta la victoria antes de entrar en campaña, o cuando asiste como espectador conmovido a los sublimes horrores de la guerra, vemos siempre en él al poeta, pero buscamos vanamente al General en Jefe ${ }^{60}$.

Los cuestionamientos a la guerra se exacerbaron y radicalizaron más aún cuando, en mayo de 1866, se conocieron los términos del Tratado de la Triple Alianza ${ }^{61}$. Publicados en La América de Buenos Aires fueron reproducidos parcialmente y comentados por los redactores de la prensa federal entrerriana quienes encontraron nuevas evidencias en sus cláusulas para reprobar la guerra. Con la publicación del tratado, la verdadera intención de los aliados — «subyugar» a Paraguay_ era inocultable:

Pocas veces habrá tenido lugar una guerra más impopular que la presente, sobre todo, después de conocido el tratado secreto, del cual resulta, que en vez de

59 El 2 de mayo se produjo un ataque sorpresa de las fuerzas paraguayas en Estero Bellaco. Sin embargo, luego del éxito inicial, un contraataque aliado provocó la retirada de los paraguayos, que sufrieron entre 1.300 y 2.300 bajas, de los cuales 300 fueron hechos prisioneros. Las bajas aliadas sumaron un poco más de 2.000 hombres. Los partes oficiales celebraron el triunfo aliado. El Uruguay publicó los partes oficiales de Mitre, Paunero, Gelly y Obes, y Nicanor Cáceres en su edición del 14-5-1865 (HUNLP).

60 El Paraná, 25-5-1866 (HUNLP).

${ }^{61}$ Los términos del Tratado fueron divulgados por la diplomacia del gobierno británico y se dieron a conocer a través de su publicación en diarios ingleses. Fueron reproducidos en Argentina por La América de Buenos Aires en sus ediciones del 5 y el 6 de mayo de 1866 . Su divulgación tuvo repercusiones inmediatas provocando críticas y reacciones condenatorias para el Imperio y sus aliados, no sólo en Argentina, sino también en otros países americanos como Perú, Bolivia, Chile, Ecuador y Colombia. En Paraguay fue reproducido íntegramente por El Semanario de Asunción el 11 de agosto. 


\begin{abstract}
ir a regenerar a un pueblo, a quitarle a su tirano, las armas de los ejércitos aliados, van a conquistar, a imponer, a arrebatar la libertad de una nación. (...) Nosotros hemos reivindicado nuestro honor ofendido, pisando el territorio enemigo. Los que quieran extender sus límites que lo hagan por su cuenta62.
\end{abstract}

De esta manera los fundamentos del gobierno de Mitre sobre la legitimidad del conflicto fueron puestos en cuestión y los argumentos en contra de la alianza con Brasil cobraron nuevo vigor. El pueblo argentino ya había reivindicado su honor expulsando a los paraguayos de su territorio, por lo tanto, se encontraba combatiendo por "propósitos inocuos» ya que las finalidades de la guerra le eran ajenas. Esta se llevaba a cabo únicamente por la conveniencia del Imperio brasileño, que era el verdadero enemigo del país.

Retomando los argumentos desplegados en 1864, los periódicos federales recordaban una y otra vez a sus lectores los motivos por los cuales Brasil no podía ser un aliado: su carácter de esclavista y monárquico lo asociaban a la barbarie y el despotismo; valores que - siempre se recalcaba - eran opuestos al republicanismo y la libertad, sostenidos por las repúblicas del Plata desde las guerras de la Independencia y afirmados en $\operatorname{Caseros}^{63}$. Asimismo, la política exterior brasileña era históricamente expansionista y tras la guerra con el Paraguay se escondía el objetivo de dominar toda la región. Por ejemplo, en un editorial de mayo de 1866 El Porvenir se preguntaba: «¿Qué viene buscando el Brasil a esta parte del continente (...)?». La respuesta era clara: «ensanchar sus fronteras, que algún día tocarán las orillas de los dos océanos» ${ }^{64}$.

Frente a Brasil, que era el verdadero enemigo, se contraponía un Paraguay con rasgos civilizados que - según se señalaba con insistencia - los periódicos unitarios se empeñaban en denegarle. Allí regía el republicanismo y no existía la esclavitud. Asimismo, su ejército estaba compuesto de soldados bravos y valientes - virtud que compartían con la tropa del ejército argentino- que luchaban temerariamente por defender a su patria, frente a tropas brasileñas compuestas de cobardes y brutos «macacos».

Entonces, el pueblo paraguayo y el pueblo argentino eran las víctimas del Imperio del Brasil. De modo que el fin inmediato de la guerra era necesario. Así lo expresaba el corresponsal de El Paraná en el frente, luego de la derrota de Curupayti:

[Mitre] debe evitar que corra más sangre de argentinos y paraguayos, que es sangre de americanos y republicanos, derramada en provecho del imperio para
62 El Paraná, 9-7-1866 (HUNLP).
63 El Paraná, 1-10-1866 (HUNLP).
64 "La misión del congreso", El Porvenir, 23-5-1866 (HUNLP). 
conquistar un pedazo de tierra de héroes. Que mande Brasil sus cobardes soldados y sus naves piratas van a encontrar las tumbas y el oprobio ${ }^{65}$.

Todas estas razones de oposición aparecían subordinadas al argumento central para impugnar la guerra: esta era ilegítima porque no era una «guerra nacional» sino una guerra de «partidos». En términos de El Eco Entrerriano, se trataba de «un pud-puri detestable de unitarios y brasileros» ${ }^{66}$. Esta alianza no lo era sólo contra el Paraguay, sino también contra el partido federal y Entre Ríos. De esta forma, en los periódicos federales se anudaba el destino del Paraguay al de Entre Ríos y los federales:

[La prensa liberal] dice que la provincia de Entre Ríos es la propiedad particular de la barbarie. Lo mismo dice de Paraguay. Los bárbaros necesitan someterse por la fuerza de la civilización y los bárbaros entrerrianos serán sometidos como los bárbaros paraguayos por la razón o la fuerza ${ }^{67}$.

Por lo tanto, en los periódicos federales las críticas a la guerra estaban ligadas y subordinadas al eje central del discurso político, la impugnación al régimen de Mitre. En el discurso del federalismo, la guerra era sólo una de las formas mediante las cuales el «partido unitario» aspiraba a destruir al Partido Federal y a uno de sus últimos bastiones: la provincia de Entre Ríos.

En suma, luego del interregno entre los meses de abril y diciembre de 1865 , fueron retomados los argumentos principales que la prensa federal entrerriana había sostenido en los inicios del conflicto: el enemigo del pueblo argentino era Brasil - y no Paraguay - y el conflicto era de naturaleza netamente partidaria. Mediante esta caracterización los redactores legitimaban la resistencia a la guerra.

Sin embargo, esto no se traducía en un apoyo explícito al régimen de López. Posiblemente, el apoyo de Urquiza a la Triple Alianza y la falta de una resistencia política articulada contra el régimen de Mitre, fuesen impedimentos para incorporar la defensa de López al discurso periodístico. No obstante, los redactores intentaban contrarrestar la extendida propaganda en su contra. Así, los clásicos calificativos utilizados por la prensa porteña y unitaria para referirse al Paraguay y a López («hordas de salvajes»; «bárbaro»; «déspota»; «tirano») eran también reproducidos en los periódicos federales, pero entrecomillados. De esta forma, sin correrse del repertorio de

\footnotetext{
65 El Paraná, 1-10-1866 (HUNLP).

66 "La opinión de Entre Ríos", El Eco de Entre Ríos, 16-7-1866 (HUNLP).

67 "A la amenaza sigue el insulto", El Porvenir, 20-6-1866. Una idea similar en “A civilizarnos”, El Porvenir, 18-7-1866 (HUNLP).
} 
calificativos oficialmente aceptado para referirse al Paraguay como enemigo de la Argentina en la coyuntura de esta guerra, los lectores podían entender que se trataba de términos que pertenecían a un vocabulario ajeno y captar rápidamente la ironía con que esas expresiones y vocablos eran utilizados. Otro recurso argumentativo común era comparar el régimen político paraguayo, con los imperantes en Brasil, en la Banda Oriental y en la Argentina. En tal comparación, estos últimos resultaban ser igual o más «bárbaros» y «despóticos» que el vigente en Paraguay, por lo tanto, ni el emperador brasileño, ni el General Flores, ni el presidente Mitre tenían autoridad moral para liberar al pueblo paraguayo del «despotismo». Incluso, en una larga editorial de El Porvenir de mayo de 1866, se agregaba a estos argumentos el de que el pueblo paraguayo estaba «embrutecido», debido a la perdurable influencia del sistema jesuita y no al sistema político del mariscal ${ }^{68}$. Por otro lado, si bien no de manera sistemática, se lo describía a López como un hombre con «proceder elevado y caballeresco», conocedor de la cultura europea y con un refinado gusto, muy diferente a un «bárbaro de las selvas paraguayas ${ }^{69}$.

Además, se procuraba desligarlo de su responsabilidad en el inicio de la guerra. ¿No había sido acaso Mitre quien con su «inmoderación»y «torpeza» había «obligado» a López a llevar a cabo la invasión a Corrientes?, se preguntaba Floreano Zapata en las páginas de El Eco de Entre Ríos en julio de 1866. Para él no cabían dudas:

Estamos seguros que si el General Mitre hubiese procedido de otro modo y hubiera guardado el carácter que le convenía a la Nación guardar, «las hordas Paraguayas» no hubiesen caído sobre Corrientes como «aves de rapiña» y no habría en medio de la cuestión presente un lago de sangre como el que existe ${ }^{70}$.

Hacia el mes de octubre, el discurso de los periódicos federales se radicalizó aún más, en coincidencia con el inicio de un nuevo ciclo de levantamientos federales en el interior, que demandó el despliegue de una gran fuerza represiva por parte del gobierno nacional y alentó las esperanzas de los federales entrerrianos en el fin cercano del gobierno de Mitre. Como consecuencia, de las críticas a Mitre se pasó rápidamente al llamado a la insurrección contra las autoridades nacionales. Un ejemplo del tono exaltado de la prensa federal, lo ofrece a fines de noviembre El Eco de Entre Ríos que arengaba a sus lectores pidiendo "Que [la insurrección] venga cuanto antes y se incendie la

\footnotetext{
68 "Los tránsfugas invocando a la patria”, El Porvenir, 12-07-1866 (HUNLP).

69 “Invitación”, El Porvenir, 8-08-1866 (HUNLP).

70 "Levanten nuestros cargos", El Eco de Entre Ríos, 28-7-1866 (HUNLP).
} 
República y se reduzcan a carbones los elementos que sostienen este orden de $\cos a s{ }^{71}$.

Entre noviembre de 1866 y febrero de 1867, la posibilidad de un triunfo de la «reacción» contra el gobierno nacional se volvió el tema dominante. En artículos, cartas y editoriales se juzgaba como necesaria la resistencia armada al orden político imperante, se esperaba el levantamiento generalizado de los «pueblos de la República» y se aplaudían las victorias de las montoneras federales. Si bien continuó la prédica contra la guerra, ésta pasó a un segundo plano ya que se confiaba en que si los federales triunfaban, vendría la paz.

Fue en este contexto de radicalización política - y discursiva - que en la prensa federal se hizo explícito el apoyo al régimen de López y al Paraguay. Este se manifestó en enero de 1867 cuando en notas publicadas en El Porvenir y El Paraná, se celebró el nombramiento del santafesino Telmo López como general de reserva del ejército paraguayo. Sin ambages, Olegario Andrade escribía:

Este amigo (...) ha merecido del Gobierno de aquella República hermana, por cuya causa, que es causa de derecho y de la justicia, abandonó hace más de un año su patria, para ir a servirla como soldado de la libertad.

[Telmo López], este hermano de Dios y en la democracia, en el elevado puesto que hoy ocupa, sabrá colocarse a la altura de sus antecedentes y corresponder con brillo a la confianza del gobierno paraguayo y a las legítimas esperanzas que sus amigos hace mucho tiempo tenemos depositadas en él. ¡Fe y adelante! Joven guerrero, que el día del triunfo del Paraguay no está lejano y ¡la hora de la redención de vuestra patria se acerca ya!72

Sin embargo, esta manifestación clara de apoyo a López y a Paraguay no se repitió en las semanas siguientes. Si bien los periódicos serían clausurados poco tiempo después (lo cual evitó, lógicamente, la posibilidad de que se publicasen otros manifiestos similares), la defensa del Paraguay tampoco tuvo un lugar notorio en el discurso de los periódicos que emergieron posteriormente ${ }^{73}$. Consideramos que la casi ausencia de una prosa «militante» a favor del Paraguay y del régimen del mariscal López, obedece al lugar que las críticas a la guerra tenían en el discurso periodístico, un lugar se-

71 "La Reacción”, El Eco de Entre Ríos, 30-11-1866 (HUNLP).

72 El Porvenir, “Telmo López”, reproducido en El Paraná, 11-1-1867 (HUNLP).

73 Seguramente, la excepción fuese el periódico El Paraguay que se publicó durante unos meses en el año 1867, del cual no conocemos sus fuentes de financiación ni los vínculos políticos de sus editores. Lamentablemente, tampoco hemos encontrado ejemplares del mismo para su consulta. 
cundario y subordinado a la disputa con el gobierno de Mitre y a la defensa del federalismo.

Mientras la guerra continuaba su curso, el 27 de enero de 1867, el Ministro del Interior Guillermo Rawson le comunicó al gobernador de la provincia José María Domínguez la orden de clausura de El Porvenir, El Pueblo Entrerriano, El Eco de Entre Ríos y El Paraná, debido a que habían tomado «una dirección incompatible con el orden nacional y con los deberes que al Gobierno General incumben en épocas como la presente» ${ }^{74}$.

La clausura de los periódicos no fue una sorpresa. Ya en el mes de agosto de 1866, el gobierno nacional había ordenado clausurar el Eco de Entre Ríos, de modo que la edición del periódico se había interrumpido hasta el mes de noviembre, cuando se reabrió la imprenta ${ }^{75}$. Y a principios de enero de 1867, un grupo de desconocidos incendió la imprenta de El Eco, por lo que para cuando llegó la segunda orden de su clausura a fines de dicho mes, este periódico ya no se editaba ${ }^{76}$.

El gobernador Domínguez acató inmediatamente la orden de clausura. En opinión de Urquiza, el gobierno de la provincia debía «evitar, mientras las circunstancias lo exijan, que ningún periódico en la provincia, cualesquiera que sea su título, escriba con el desenfreno que se ha hecho» ${ }^{77}$. Esto supuso el fin de El Eco de Entre Ríos, El Porvenir, El Pueblo Entrerriano y El Paraná, pero no el fin de la prédica contraria a la guerra en la provincia. Días más tarde, se fundaron nuevos periódicos con la anuencia de Urquiza, que continuaron con una línea editorial similar, aunque algo más moderada ${ }^{78}$.

CONSIDERACIONES FINALES: OPOSICIÓN A LA GUERRA Y ANTAGONISMOS PARTIDARIOS EN UN ESPACIO REGIONAL

Desde los inicios del conflicto regional en 1864 que llevaría a la creación de la Triple Alianza contra Paraguay, la prensa federal entrerriana mostró una

74 Circular del Ministerio del Interior al Gobierno de Entre Ríos, 27 de enero de 1867, citado en Vázquez, 1970: 91.

75 "Libertad de Imprenta", El Paraná, 5-9-1866 (HUNLP). "Una palabra", El Eco, 19/11/1866 (HUNLP). “El Pueblo Entrerriano”, El Eco de Entrerríos, 17-12-1866 (HUNLP).

76 "Incendio", El Porvenir, 9-1-1867 (HUNLP).

77 Justo José de Urquiza a J. M. Domínguez, San José, 31 de enero de 1867, AGN, FU, 1751.

78 Nos referimos a La Regeneración y a El País ambos en la ciudad de Gualegaychú. 
constante oposición a la guerra. Sin embargo, la crítica a la guerra no fue lineal a lo largo del período aquí analizado. La subordinación política de los periódicos al poder de Urquiza, llevaron a cambios bruscos de discurso de acuerdo a la situación política interna de Entre Ríos y a los intereses del caudillo. Como se vio, los discursos fuertemente opositores cesaron cuando se hizo público el apoyo de Urquiza a la guerra contra Paraguay en abril de 1865. Pero cuando dejó de ser necesaria la moderación de la prensa federal para mantener el orden político en la provincia, otra vez emergieron las críticas a la guerra.

La oposición a la guerra y al régimen mitrista no implicaba el cuestionamiento a la existencia de una Nación argentina. En las notas y editoriales publicadas (y también en la correspondencia privada) los federales de Entre Ríos remarcaban recurrentemente su calidad de entrerrianos y se reconocían como argentinos. Sin embargo, la adscripción a la Nación argentina aparecía más débil, menos definida y con frecuencia en un segundo plano frente a la más clara y recurrente adscripción entrerriana ${ }^{79}$. Sin duda, era una etapa en la cual fuertes identidades provinciales convivían - a veces en tensión - con una emergente identidad nacional, todavía no totalmente formada. No obstante, los discursos periodísticos federales no contraponían la nación a la provincia (ni los «entrerrianos» a los «argentinos»). Lo que estaba en disputa, era quién encarnaba los verdaderos intereses nacionales. Como se vio a lo largo de este trabajo, para los federales el gobierno de Mitre no representaba a la Nación, sino sus intereses particulares, los del partido «unitario». En suma, la guerra contra Paraguay (sobre todo a partir de 1866) no podía ser una «causa nacional» ${ }^{80}$.

Las críticas a la guerra se realizaron apelando al imaginario político decimonónico y en el lenguaje que articulaba los debates y disputas políticas en la región rioplatense de mediados del siglo XIX. Este discurso se configuraba en torno a pares dicotómicos: libertad versus tiranía; progreso versus atraso; civilización versus barbarie. Tales oposiciones estuvieron presentes en todos los discursos sobre la guerra que circularon a través de la prensa, pues eran un componente central del ideario liberal ampliamente compartido por las dirigencias rioplatenses. La diferencia entre los discursos opositores y defensores de la guerra residía, sobre todo, en la definición de quiénes ocupaban uno $u$ otro lugar en ese esquema discursivo.

79 Además, «ser entrerriano» implicaba una clara adscripción política: para el federalismo provincial, un verdadero entrerriano era necesariamente federal. Un análisis de la identidad federal entrerriana en Schmit, 2004.

80 Un análisis sobre el concepto de Nación en los periódicos del litoral durante la guerra en Baratta, 2013: 75-96. 
Entonces, los periódicos entrerrianos formaban parte de un entramado discursivo de alcance regional en el que similares argumentos se repetían en distintos espacios. En tal sentido, los tópicos centrales en torno a los cuales se estructuraban la denuncia a la Triple Alianza y la oposición a la guerra se hallan también en otras provincias y en la prensa Paraguaya: la impugnación a Brasil por sus ambiciones expansionistas, su sistema monárquico y la esclavitud; y la defensa de Paraguay en tanto bastión del republicanismo y de la libertad ${ }^{81}$.

Sin embargo, en los periódicos entrerrianos la oposición a la guerra no se basó en una defensa invariable y explícita del Paraguay ni en una exaltación de la figura de López, sino que estuvo marcada por una censura a la alianza con Brasil y, sobre todo, por una sistemática impugnación a las políticas del presidente Mitre.

En tal sentido, las críticas a la guerra formaban parte de un discurso político cuyo fin era la oposición al gobierno de Mitre y a las políticas de su partido. Los términos con los que se definía el enfrentamiento entre unitarios y federales se solapaban con los usados para definir el carácter del conflicto bélico con Paraguay. Para los federales entrerrianos, la guerra cobró gran importancia en tanto que la Triple Alianza era interpretada como una expresión de los intereses de los porteños y unitarios en la Argentina. Así, la defensa del «pueblo paraguayo» y del mariscal López, es marginal en el discurso y se presenta subordinada al objetivo principal: resistir a las políticas del presidente Mitre y a las aspiraciones de hegemonía del «partido unitario». Por tal motivo, la defensa del partido blanco frente a la invasión de Flores fue mucho más vigorosa que la ofrecida al Paraguay. En el primer caso, los vínculos partidarios que unían a los blancos con los federales de Entre Ríos eran estrechos y de larga data. Apoyar al partido blanco, era casi equivalente a defender al federalismo. Esta similitud no era tan evidente en el caso de defensa del régimen de López y el Paraguay, cuyos vínculos con el federalismo entrerriano eran mucho más recientes, menos profundos y extendidos.

\section{BiBLIOGRAFÍA}

Alabart, Mónica, "Los desbandes de Basualdo y Toledo: hacia la fractura del federalismo entrerriano", Roberto Schmit (comp.), Caudillos, politica e instituciones

81 La repetición de tópicos y argumentos en la prensa regional es fácilmente observable mediante un recorrido por las investigaciones sobre la prensa del período. Un análisis comparativo de la prensa argentina y paraguaya en Johansson y Sujatovich, 2012: 99-111. Referencias a discursos regionales sobre la guerra en Whigham, 2012b: 157-180. 
en los orígenes de la Nación Argentina, Buenos Aires, Ediciones UNGS, 2015: 101-131.

Archivo del General Mitre, tomo II: Guerra del Paraguay, Buenos Aires, La Nación, 1911.

Baratta, María Victoria, "La identidad nacional durante la Guerra del Paraguay. Representaciones, lenguajes políticos y conceptos en el diario La Nación Argentina (1862-1870)", Almanack. Guarulhos, 3 (San Pablo, 2012a): 82-98.

Baratta, María Victoria, "La oposición a la Guerra del Paraguay en Buenos Aires. Un análisis de las representaciones de la nación argentina en el periódico La América", Revista Electrónica da ANPHLAC,13 (2012b): 83-108, http://revista.anphlac.org. br/index.php/revista.

Baratta, María Victoria, "El litoral y la batalla de pluma: la identidad nacional argentina en los periódicos de Entre Ríos y Corrientes durante la Guerra del Paraguay (1864-1870)”, Folia Histórica del Nordeste, 21 (Resistencia, 2013): 75-96.

Baratta, María Victoria, "Representaciones de Paraguay en Argentina durante la Guerra de la Triple Alianza, 1864-1870”, Revista SURES, 4 (Foz de Iguazú, 2014): 41-53, https://ojs.unila.edu.br/ojs/index.php/sures.

Bosch, Beatriz, "Urquiza y la Guerra de la Triple Alianza", Boletín de la Academia Nacional de la Historia, XXXIV/Segunda Sección (Buenos Aires, 1963): 822-827.

Braschi, Dardo, La Guerra de la Triple Alianza. A través de los periódicos Correntinos. 1865-1870, Corrientes, Moglia Ediciones, 2003.

Braschi, Dardo, La Guerra del Paraguay en la Provincia de Corrientes. Impactos políticos, daños y consecuencias en la población civil, Corrientes, Moglia Ediciones, 2014.

Braschi, Dardo, Politica correntina en tiempos de guerra 1865-1870, Corrientes, Moglia Ediciones, 2016.

Brezzo, Liliana (coord.), "Dossier: 150 años de la Guerra del Paraguay: nuevos enfoques teóricos y perspectivas historiográficas. Primera parte”, Folia Histórica del Nordeste, 24 (Resistencia, 2015a): 95-162.

Brezzo, Liliana (ed.), La guerra del Paraguay en primera persona. Testimonios Inéditos. Fondo Estanislao Zeballos, Asunción del Paraguay, Editorial Tiempo de Historia, 2015 b.

Brezzo, Liliana (coord.), "Dossier: 150 años de la Guerra del Paraguay: nuevos enfoques teóricos y perspectivas historiográficas. Segunda parte”, Folia Histórica del Nordeste, 25 (Resistencia, 2016): 91-186.

Buchbinder, Pablo, "Gente decente y paysanos contra la guerra: dimensiones de la resistencia a la Triple Alianza en la provincia de Corrientes", Iberoamericana, XII/47 (Berlín, 2012): 29-48. 
Caballero Campos, Hérib y Ferreira Segovia, Cayetano, "El Periodismo de Guerra en el Paraguay (1864-1870)", Nuevo Mundo Mundos Nuevos (París, 2006), http:// nuevomundo.revues.org/1384.

Capdevila, Luc, Una guerra total: Paraguay, 1864-1870. Ensayo de historia del tiempo presente, Buenos Aires, SB, 2010.

Chávez, Fermín, Vida y muerte de López Jordán, Buenos Aires, Theoría, 1957.

De la Fuente, Ariel, Los hijos de Facundo. Caudillos y montoneras en la provincia de La Rioja durante el proceso de formación del Estado Nacional Argentino (1853-1870), Buenos Aires, Prometeo, 2007.

De Marco, Miguel Ángel, Corresponsales en acción: crónicas de la Guerra del Paraguay: "La Tribuna"(1865-1866), Buenos Aires, Librería Histórica, 2003.

Doratioto, Francisco Fernando, Maldita Guerra. Nova historia da Guerra do Paraguai, Sao Paulo, Campanhia das letras, 2002.

Duarte, María Amalia, Urquiza y López Jordán, Buenos Aires, Editorial Platero, 1974.

Garavaglia, Juan Carlos, "Guerra y finanzas en la Argentina unificada, 1864-1872: la guerra del Paraguay y la misión De la Riestra en Londres" Quinto Sol, XX/3 (La Pampa, 2016): 1-33.

Guinot, Dolores Luna, La Guerra Grande: 1864-1870: La Triple Alianza secreta contra el Paraguay, Madrid, Imagine Press Ediciones, 2005.

Johansson, María Lucrecia, "Inspiración bajo el estampido del cañón. Tensiones en torno a la escritura de la prensa en los periódicos de trinchera paraguayos" (18671869), Folia Histórica del Nordeste, 20 (Resistencia, 2011): 117-138.

Johansson, María Lucrecia, "Paraguay contra el monstruo anti-republicano. El discurso periodístico paraguayo durante la Guerra de la Triple Alianza (1867-1869)", Historia Crítica, 47 (Bogotá, mayo-agosto 2012): 71-92.

Johansson, María Lucrecia y Sujatovich, Luis, "Papeles de guerra. Causas de la Guerra de la Triple Alianza a través de la prensa argentina y paraguaya (18621870)”, Revista Universum, II/27 (Talca, Chile, 2012): 99-111.

Míguez, Eduardo, "Política y partidos en la organización nacional”, Ana Laura Lanteri, (coord.), Actores e identidades en la construcción del estado nacional (Argentina, siglo XIX), Buenos Aires, Teseo, 2013: 171-210.

Navajas, María José, "Polémicas y conflictos en torno a la Guerra del Paraguay: los discursos de la prensa en Tucumán, Argentina (1864-1869)", Nuevo Mundo Mundos Nuevos (París, 2009), http://nuevomundo.revues.org/49313.

Palti, Elías, El tiempo de la política. El siglo XIX reconsiderado, Buenos Aires, siglo XXI, 2007.

Pérez, Mariana, "Un baluarte liberal en Entre Ríos. El periódico La Democracia de Gualeguaychú entre 1863 y 1867”, Roberto Schmit (ed.), Caudillos, política e 
instituciones en los orígenes de la nación Argentina. El federalismo entrerriano en el siglo XIX, Los Polvorines, Prometeo/UNGS, 2015a: 133-160.

Pérez, Mariana, "Poder político provincial y prensa federal en Entre Ríos: entre la subordinación y la autonomía (1862-1867)”, Folia Histórica del Nordeste, 24 (Resistencia, 2015b): 35-58.

Pomer, León, Cinco años de guerra civil en Argentina: 1865-1870, Buenos Aires, Amorrortu, 1986.

Sabato, Hilda, Historia de la Argentina, 1852-1890, Buenos Aires, Siglo XXI, 2012.

Schmit, Roberto, Ruina y resurrección en tiempos de guerra, Buenos Aires, Prometeo, 2004.

Silveira, Mauro César, A batalha de papel. A charge como arma na guerra contra o Paraguai, Florianópolis, Editora UFSC, 2009.

Silveira, Mauro César, "Os múltiplos papéis do jornalismo braseleiro na Guerra contra Paraguai”, Historia, 5/1 (Río Grande, 2014): 213-236.

Vázquez, Anibal, Periódicos y periodistas de Entre Ríos, Paraná, Dirección de Cultura de Entre Ríos, 1970.

Whigham, Thomas, La Guerra de la Triple Alianza, vol I. Causas e inicios del mayor conflicto bélico de América del Sur, Asunción, Taurus, 2010.

Whigham, Thomas, La Guerra de la Triple Alianza, vol. II. El triunfo de la violencia, el fracaso de la paz, Asunción, Taurus, 2011.

Whigham, Thomas, La Guerra de la Triple Alianza, vol. III. Danza de muerte y destrucción, Asunción, Taurus, 2012a.

Whigham, Thomas, "Building the Nation While Destroying the Land: Paraguayan Journalism during the Triple Aliance War, 1864-1870", Anuario de Historia de América Latina, 49 (Alemania, 2012b): 157-180.

Fecha de recepción: 6 de octubre de 2016.

Fecha de envío de las modificaciones: 20 de abril de 2017.

Fecha de aceptación: 6 de julio de 2017. 


\section{Political Conflict and the Federal Press during the Triple Alliance War. Entre Ríos, 1864-1867}

From the outbreak of the Triple Alliance War, the press was a key space for controversy and debate in the political arena. This paper analyses the federal press in Entre Rios in order to examine the political dynamics in the province and their linkage with the war. Our hypothesis is that, while the federal press exhibited constant opposition to the war, criticism was not linear throughout the period analysed here and was linked to opposition to the policies of President Bartolome Mitre and the liberal party.

KEY WORDs: federal press; Triple Alliance War; political dynamics; political representations. 